\title{
Spontaneous Spinal Epidural Hematoma in a Child with Hemophilia B
}

\author{
Erica F. Bisson, Travis Dumont, Bruce Tranmer
}

Can. J. Neurol. Sci. 2007; 34: 488-490

Central nervous system hemorrhage is an uncommon and potentially devastating event in hemophiliacs, with an incidence of $2-8 \% .^{1}$ Intraspinal hematomas account for $8.5 \%$ of CNS hemorrhages in patients with factor VIII or IX deficiencies. ${ }^{2}$ Although most reported cases in this population are secondary to trauma, there are a few reports of spontaneous hemorrhage. $3,4,5$ We present a case of spontaneous spinal epidural hematoma (SSEH) in a child with Hemophilia B, factor IX deficiency, and review the relevant management strategies.

\section{CASe}

A seven year old male in absence of known trauma and known factor IX deficiency presented a five day history of neck and arm pain. He was evaluated by his pediatrician and given a bolus of 1100 units of factor IX and another infusion of 1100 units the following day as empiric therapy. Because of persistent neck pain, a cervical MRI was obtained revealing an acute epidural hematoma ventral to the thecal sac, extending from $\mathrm{C} 2$ T3 with evidence of spinal cord compression (Figure 1A\&B). The patient immediately received an additional 3000 units of factor IX and was transferred to our hospital. He reported discomfort with neck extension, and maintained his neck in a flexed position. He denied any bowel or bladder difficulty. Initial physical exam and laboratory studies were significant for a flexed neck posture, inability to raise his arms overhead secondary to pain, and a factor IX level which was $48 \%$ of normal. No cranial neuropathy, strength or sensory abnormalities were noted. As he was neurologically intact without signs of myelopathy, immediate surgical evacuation was not recommended. He was admitted to the pediatric intensive care unit for close neurologic monitoring and started initially on twice daily infusions of factor IX which was changed to a continuous infusion of 15 units $/ \mathrm{kg} /$ hour for more consistent levels. Over the subsequent days, the patient reported improvement in his neck pain and range of motion. He was discharged home on hospital day 21 with 3000 units intravenous factor IX every 12 hours for the next 7 days. A follow up MRI at one month showed complete resolution of the epidural hematoma (Figure 2A\&B).

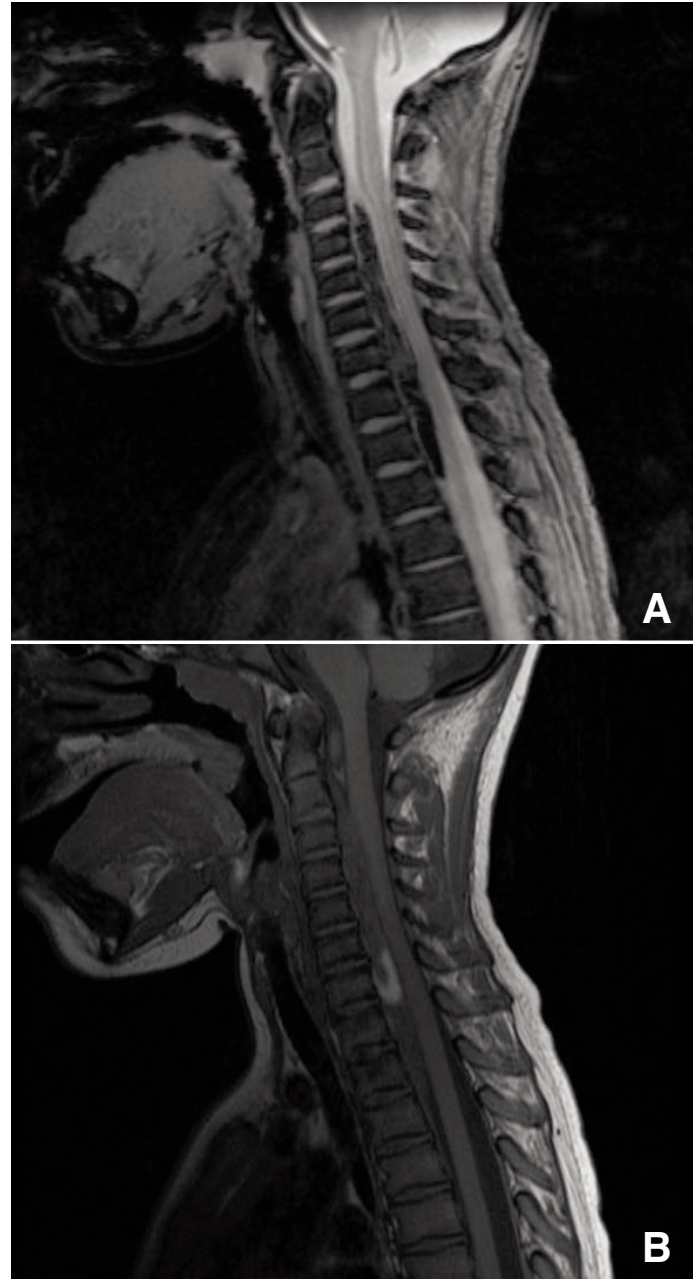

Figure 1. Sagittal gradient(A) and T1 (B) MRI respectively demonstrating an epidural hematoma posterior to C2 vertebral body with extension to the T2-3 level. Obliteration of the Subarachnoid space from C3-4 level to C7-T1 level, with posterior cord displacement and compression.

\footnotetext{
From the Department of Neurosurgery (EFB, TD), Division of Neurosurgery (BT), University of Vermont College of Medicine, Berlington, Vermont, USA.

RECEIVED APRIL 10, 2007. ACCEPTED IN FINAL FORM JULY 10, 2007.

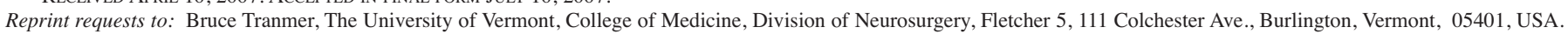



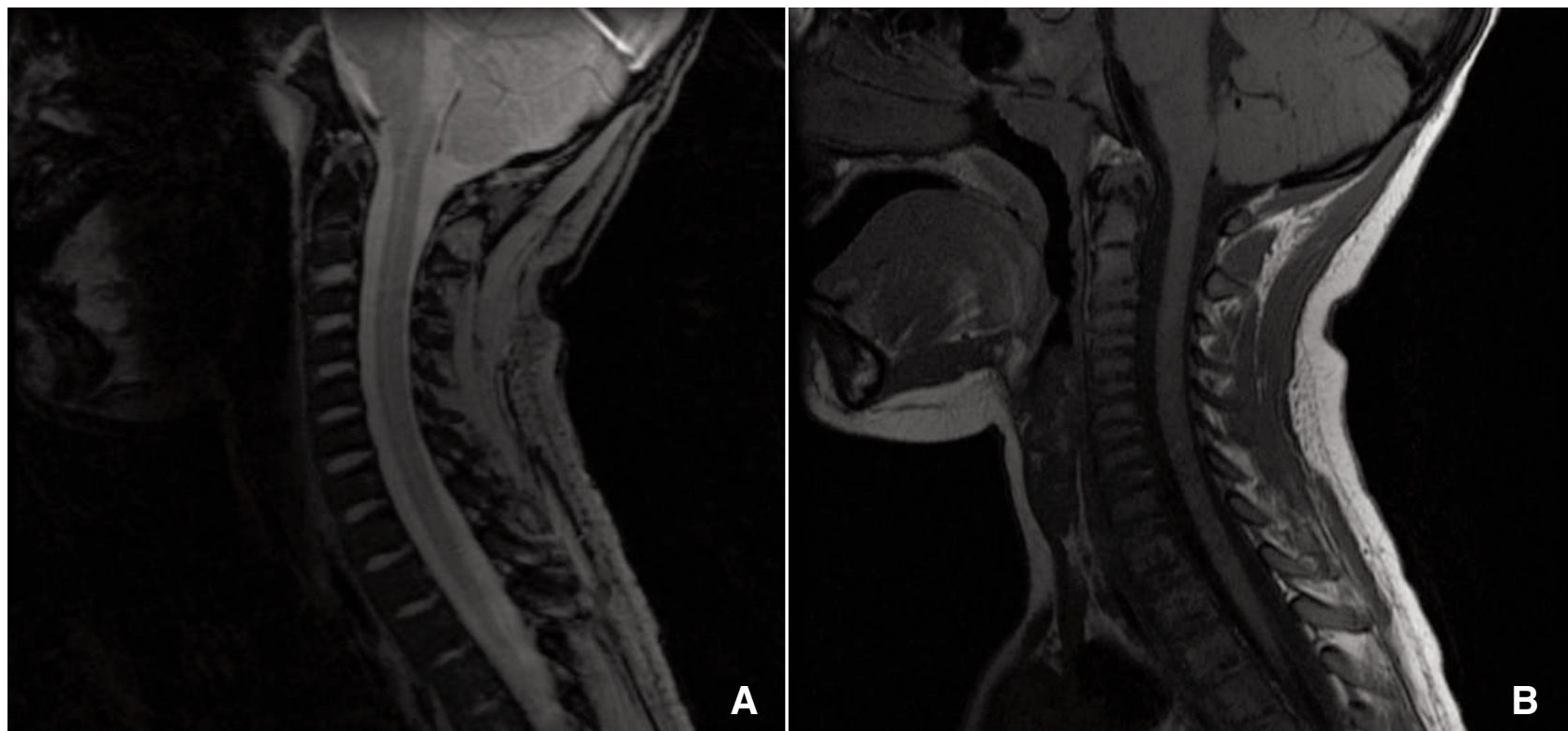

Figure 2. Sagittal gradient $(A)$ and $T 1$ (B) MRI respectively demonstrating interval resolution of epidural hematoma.

\section{DisCUSSION}

Cases of SSEH, although uncommon, can result in serious neurological deficit without acute intervention. In rare instances, patients with hemophilia develop SSEH as a result of minor trauma that can easily escalate to a fatal or disabling condition from spinal cord compression. The first case of SSEH in a hemophiliac was reported by Tellegen in $1850 .{ }^{6}$ Since that time, there have been less than seven reported cases in the literature of SSEH in hemophilia B. ${ }^{7}$ As well, a large cohort study reported the ratio of cases comparing central nervous system hemorrhages involving Hemophilia B to Hemophilia A as 1:2.75, demonstrating the paucity of cases involving Hemophilia B, which may be a reflection of lower overall incidence of Hemophilia B. ${ }^{8}$

Patients who develop spinal epidural hematoma, either traumatic or spontaneous, commonly present with a uniform constellation of symptoms including neck and/or back pain and paresis, followed by sensory deficits as well as bowel or bladder dysfunction..$^{2,5,7-9}$ However, in patients with a progressive decline in neurological status despite conservative measures, urgent decompression with evacuation of the hematoma is required.,10

Although surgery is indicated in patients with a neurologic decline, it is not without complication. Reports of patients who have undergone surgical decompression have been less than encouraging, resulting in limited benefit in return of neurological function. ${ }^{7,9}$ Moreover, multilevel laminectomy, as is usually required for adequate decompression can weaken the structural integrity of the posterior elements, which in children with increased viscoelasticity of ligaments can result in instability and progressive deformity. ${ }^{9,11}$
In our case the patient was treated conservatively through replacement of factor IX with a maintenance dose to sustain levels greater than $90 \%$ during his hospital stay and, extending into an outpatient period. Several recent case studies advise an immediate bolus of factor IX to achieve a level of $100 \%$ and then maintenance of a level between 50 and $100 \%$ for the next 14 days. ${ }^{7}$ On the other hand, several reports define as adequate an initial level of between $80-100 \%$ and maintenance level of between $30-50 \%$ for the subsequent 14 days., ${ }^{2,9}$ Prompt replacement of factor IX is associated with a decrease in morbidity, ${ }^{2}$ and when coupled with a stable patient allows for conservative management.

Radiographic evidence of spinal cord compression is often cited as an indication for surgical evacuation..$^{3,10,12}$ In hemophiliacs, with increased operative risk, it is prudent to attempt conservative measures, replacing factor levels, as an initially and potentially complete treatment option.

\section{REFERENCES}

1. Silverstein A. Intracranial bleeding in hemophilia. Arch Neurol. 1960;3:141-57.

2. Hamre MR, Haller JS. Intraspinal hematomas in hemophilia. Am J Pediatr Hematol Oncol. 1992;14:166-9.

3. Chan DT, Boet R, Poon WS, Yap F, Chan YL. Spinal shock in spontaneous cervical spinal epidural haematoma. Acta Neurochir (Wien). 2004;146:1161-2; discussion 1162-3.

4. Kingery WS, Seibel M, Date ES, Marks MP. The natural resolution of a lumbar spontaneous epidural hematoma and associated radiculopathy. Spine. 1994;19:67-9.

5. Pahapill PA, Lownie SP. Conservative treatment of acute spontaneous spinal epidural hematoma. Can J Neurol Sci. 1998; 25:159-63.

6. Schenk VW. Haemorrhages in Spinal Cord with Syringomyelia in a Patient with Haemophilia. Acta Neuropathol (Berl). 1963;27: 306-8. 
7. Sheikh AA, Abildgaard CF. Medical management of extensive spinal epidural hematoma in a child with factor IX deficiency. Pediatr Emerg Care. 1994 10:26-9.

8. Eyster ME, Gill FM, Blatt PM, Hilgartner MW, Ballard JO, Kinney TR. Central nervous system bleeding in hemophiliacs. Blood. 1978;51:1179-88.

9. Narawong D, Gibbons VP, McLaughlin JR, Bouhasin JD, Kotagal S. Conservative management of spinal epidural hematoma in hemophilia. Pediatr Neurol. 1988;4:169-71.
10. Case AS, Ramsey PS. Spontaneous epidural hematoma of the spine in pregnancy. Am J Obstet Gynecol. 2005;193:875-7.

11. Yasuoka S, Peterson HA, Laws ER, Jr., MacCarty CS. Pathogenesis and prophylaxis of postlaminectomy deformity of the spine after multiple level laminectomy: difference between children and adults. Neurosurgery. 1981;9:145-52.

12. Cakir E, Karaarslan G, Usul H, Baykal S, Kuzeyli K, Mungan I, et al. Clinical course of spontaneous spinal epidural haematoma mimicking Guillain-Barre syndrome in a child: a case report and literature review. Dev Med Child Neurol. 2004;46:838-42. 